\title{
Increased seismic hazard in Barcelona (Spain) due to soil-building resonance effects
}

\author{
Luis A. Pinzón ${ }^{\mathrm{a}}$, Luis G. Pujades ${ }^{\mathrm{a}}$, Albert Macau ${ }^{\mathrm{b}}$, and Sara Figueras ${ }^{\mathrm{b}}$ \\ ${ }^{a}$ Universitat Politècnica de Catalunya, Department of Civil and Environmental Engineering, Barcelona, Spain \\ ${ }^{\mathrm{b}}$ Institut Cartogràfic i Geològic de Catalunya, Geophysics and Seismology Area, Barcelona, Spain
}

\begin{abstract}
\end{abstract}
In this study, previous microzonation studies in Barcelona (Spain) were revisited, and available data on the predominant periods of soils in the city were compiled to develop an updated microzonation map of the city. In addition, the building database was updated and used to create a map of building fundamental periods. The crossing of soil predominant period and building fundamental period maps led to the detection of areas in which resonance phenomena and, indeed, increased amplification of the structural response are expected. Thus, zones of Barcelona were identified in which the seismic hazard is probably greater due to resonance effects. The improved microzonation maps and the detection of soil-building resonance areas contribute significantly to enhanced precision and awareness of seismic hazard and risk in Barcelona.

\section{Keywords}

Seismic resonance, soil-structure interaction, fundamental periods, local seismic hazard, H/V spectral ratios, microzonation

\section{Introduction}

Seismic risk is defined as the probability or rate of the expected cost due to earthquakes in a specific period of time. Three aspects must be considered to study and develop knowledge of seismic risk in a specific area: the hazard, exposure/vulnerability, and the value of the exposed goods. The seismic hazard defines the annual probability or rate of earthquake occurrence which is determined by: 1) seismic source studies including the geometric distribution of faults, the focal mechanism, and earthquake recurrence models, 2) calculation of ground motion prediction equations (GMPE), and 3) characterization of local effects, including soil, topographic, and induced effects such as landslides and soil liquefaction [1]. The results of a hazard study allow us to determine the exceedance probabilities of a given threshold of ground motions during a specific time period. Ground motion thresholds may be quantified in terms of macroseismic intensity, peak ground acceleration, or spectral values of the structural response, among many other parameters.

Let us focus on the local effects, specifically on-site effects due to the soil response [2]. Soil response maps usually have low resolution and they may be biased because of limitations in the quantity and geometric distribution of sampling points for which reliable information is available. It is known that anomalies can occur due to underground aquifers and/or ravines and streams responsible for draining rainwater from the highlands to the plains in large cities, among other factors. These underground anomalies are very common in most modern cities, particularly in those with rivers that cross them, those that are built on coasts, or those that have both characteristics. Typical examples of such cities in Spain, where seismic microzonation studies to evaluate site effects have been performed, are Malaga and Murcia [3,4]. 
There are two kinds of methods for characterizing the response of soil to a seismic action: experimental and numerical. The main objective of experimental methods is to determine the transfer function or the fundamental period/frequency of the surface deposits through micro-tremor, seismic, or noise records. In this respect, the spectral $\mathrm{H} / \mathrm{V}$ ratio is a well-known technique [5].

To consider the effects of soil in seismic hazard evaluations, areas with soils that behave in a very similar way when an earthquake occurs are grouped together. This zonation can be carried out according to parameters that describe the ground motion, such as macroseismic intensity, spectral acceleration, and, in the case of this study, the fundamental period of the soil.

Resonance is as an important factor to consider in the effects of local geology on the amplification of seismic action [6]. Resonance is a well-known phenomenon in physics. It is produced when a vibrating object is subjected to a periodic force whose period is close to the characteristic period of the object. Hence, relatively small forces may cause great amplitudes of the oscillating system. Thus, the object progressively vibrates and increases the amplitude of the movement after each successive cycle of the force.

This phenomenon can also be found in buildings due to earthquake actions. In these cases, the building would be the "object" and the seismic action the "force". In a simplified way, each building can be defined as a damped single-degree-of-freedom system with a vibration period, T. With this simplification, a period can be assigned to each single building. In addition to the causative fault features and propagation path through rock formations, seismic actions are affected by soil amplification effects. The typical frequencies and amplitudes of seismic waves vary depending on the soil type. Rigid media, such as rocky and stiff soils, do not amplify the seismic motion, while soft soils amplify specific frequencies depending on the soil characteristics. By crossing building vibration eigen periods and predominant soil frequencies, resonant zones can be detected and analyzed, due to the similarity between the periods of the structures and the periods of the expected seismic actions. In civil engineering, the study of this effect complements the soilstructure interaction (SSI) field. SSI is a very important factor that must be considered in the seismic design of structures [7-9].

In Barcelona, seismic microzonation studies first began at the end of the 1990s and early 2000s. Initial research took advantage of existing geological maps and geotechnical soundings [10-12]. Data concerning $\mathrm{H} / \mathrm{V}$ spectral ratios [13] were also used. As a result of a soil response modelling process, four homogeneous and regular soil zones were defined in lines approximately parallel to the coast (Fig. 1a). The first zone, with soft soils, is close to the coastline and the fourth one, of rocky outcrops and hard soils, is in the highest zone of the city (Fig. 1b). The excellent correlation between elevation and soil type is evident. Intermediate soft and hard soil zones were defined by two areas that border the first and fourth zones respectively [10]. 
In recent years, Cadet et al. [14] used all the available information and complemented it with new array measurements to characterize each zone by means of fundamental resonance frequencies and shear-wave velocity profiles. These authors proposed an average soil for each zone and a standard reference rock site.

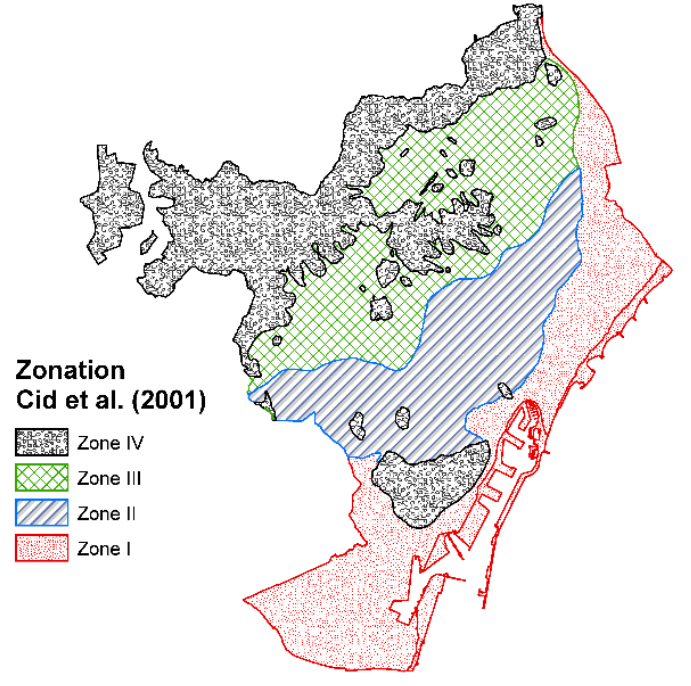

(a)

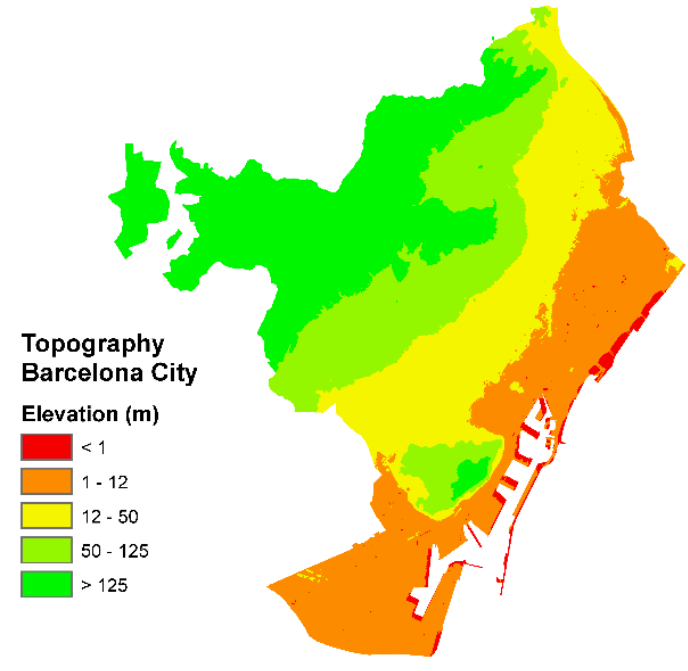

(b)

Fig. 1. (a) Microzonation map of Barcelona city and (b) topography of the city

The aim of this study was to analyze seismic soil effects in Barcelona, including likely soil-building resonance effects. The starting point was the construction of a fundamental period map of buildings in Barcelona. A second objective was to develop an updated, improved seismic microzonation map of Barcelona, based on the integration of existing data. Finally, a correlation analysis of soil and building predominant period maps was designed to detect and quantify areas in which resonance phenomena and amplification of the structural response are expected.

\section{Building period map}

In Barcelona, approximately 71,000 of the 80,715 lots in the city are occupied by buildings. Our research group has an excellent database, provided by Barcelona City Council's Civil Protection Services, with detailed information on the typology, age, and geometric characteristics of over $90 \%$ of these buildings [15]. It is estimated that this information corresponds to over $96 \%$ of the city's residential buildings. We used this database to develop the map of fundamental periods of the city's buildings.

Information on structural typology (masonry, concrete, wood, steel, and others) and the number of stories was used to estimate the fundamental periods of vibration. Then, the ArcMap GIS tool was used to generate the map of fundamental periods of the buildings. Before the periods were estimated, the buildings were separated into typologies. For this purpose, the RISK-UE building typology matrix was used [16]. The identification of the typology of every building in Barcelona was previously defined by Lantada et al. [15]. Eight main typologies were used (see Table 1). 
Table 1. Structural typologies and coefficient, $C_{t}$, used in this study. (URM: unreinforced masonry; RC: reinforced concrete)

\begin{tabular}{|c|l|c|}
\hline Risk-UE Typologies & \multicolumn{1}{|c|}{ Description } & \multirow{1}{|c|}{$\boldsymbol{C}_{\boldsymbol{t}}$} \\
\hline M31 & URM bearing walls with wooden slabs & \multirow{3}{*}{0.050} \\
\hline M32 & URM bearing walls with masonry vaults & \\
\hline M33 & URM bearing walls with composite steel and masonry slabs & \\
\hline M34 & URM bearing walls with RC slabs & 0.075 \\
\hline RC32 & RC irregular frames with URM infill walls & \multirow{2}{*}{0.085} \\
\hline S3 & Steel frames with URM infill walls & \\
\hline S5 & Steel and RC composite systems & 0.050 \\
\hline W & Wood structures &
\end{tabular}

To estimate the fundamental periods of each building, the approximate equation of the Eurocode 8 (EC-8) [17] was used.

$$
T_{1}=C_{t} H^{3 / 4}
$$

Where $C_{t}$ is the variation coefficient and $\mathrm{H}$ is the building height in meters (m). For each structural typology, a value of $C_{t}$ was defined (see Table 1).

The approximate fundamental period of each building can also be obtained from other structural regulations [18]. Fig. 2 shows the results obtained after the assignment of the period to each building. Different colors have been assigned to different ranges of periods.
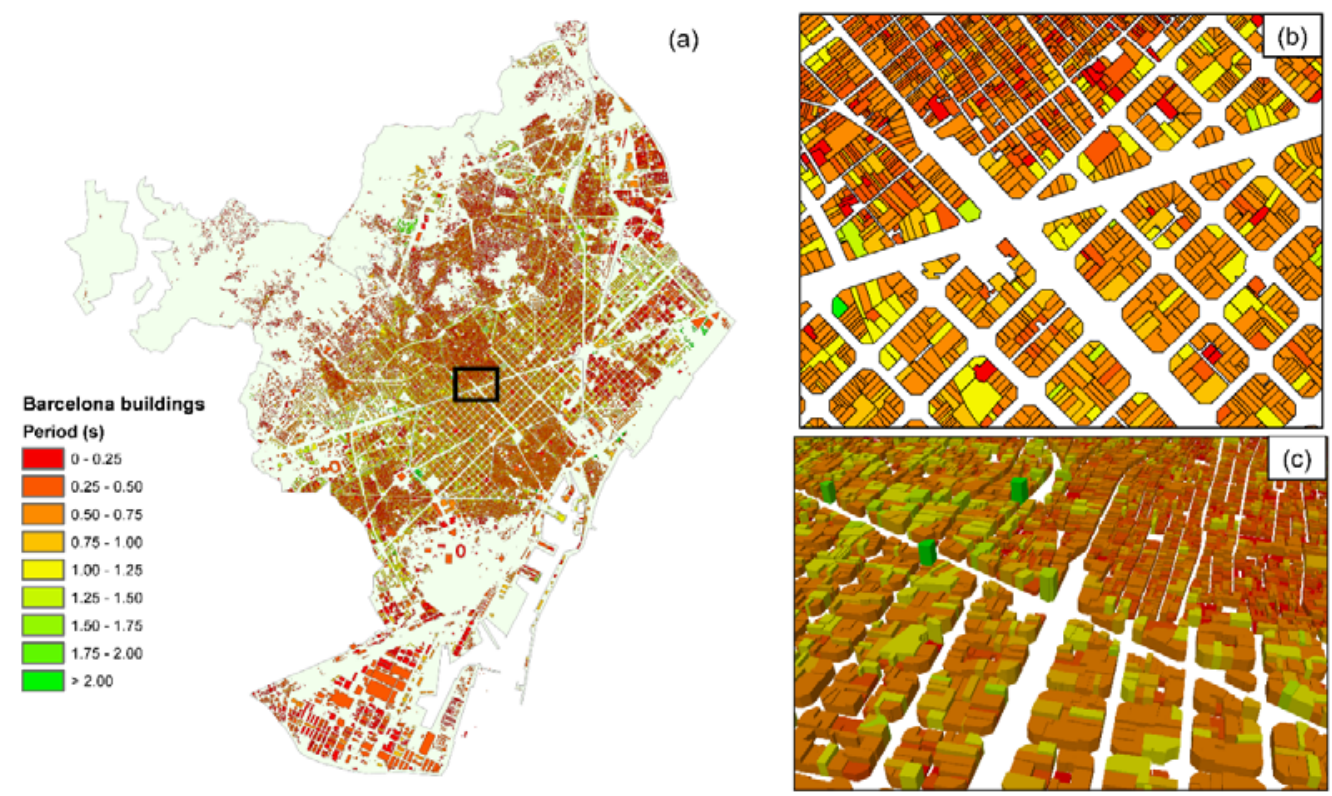

Fig. 2. (a) Map with the estimated fundamental period of the building database of Barcelona, (b) zoom-in the cross between Diagonal Ave. and Passeig de Gracia street and (c) 3D view of (b).

\section{Soil period map}

One of the aims of this study was to develop an improved microzonation map based on soil response periods. As a starting point, we compiled all the information on Barcelona's soils that had been obtained by experimental methods. This information was integrated into a geo-referenced, homogeneous database 
including information on the fundamental soil period obtained by $\mathrm{H} / \mathrm{V}$ measurements $[13,14,19,20]$. The available data, together with the corresponding references, are shown in Table 2.

Table 2. Available soil data from Barcelona used in this study.

\begin{tabular}{|c|l|}
\hline Author & \multicolumn{1}{c|}{ Description of the study } \\
\hline $\begin{array}{c}\text { Alfaro et al. } \\
{[13]}\end{array}$ & $\begin{array}{l}\text { Micrometer field survey carried out in Barcelona using a high dynamic range accelerometer to obtain } \\
\text { fundamental periods based on H/V. The H/V spectral ratio was computed in a range between } 0.05 \text { and } \\
15 \mathrm{~Hz} .\end{array}$ \\
\hline $\begin{array}{c}\text { Cadet et al. } \\
{[14]}\end{array}$ & $\begin{array}{l}\text { Ambient noise array measurements in Barcelona with a Lennartz LE-3D sensor (cut-off frequency of } \\
0.2 \mathrm{~Hz} \text { ) and CityShark acquisition system. }\end{array}$ \\
\hline $\begin{array}{c}\text { Santos- } \\
\text { Assuncao et } \\
\text { al. [19] }\end{array}$ & $\begin{array}{l}\text { GPR data were used to define the most probable area affected by streams and paleochannels. Then, } \\
\text { vibration measurement points were selected considering these previous results. After selection of the } \\
\text { measurement point, the fundamental period of soil response was determined by the H/V method. The } \\
\text { ambient noise measures were obtained with a Tromino seismometer. }\end{array}$ \\
\hline $\begin{array}{c}\text { Macau et al. } \\
{[20]}\end{array}$ & $\begin{array}{l}\mathrm{H} / \mathrm{V} \text { measurements were estimated along the Llobregat Delta, Barcelona. The seismic ambient noise } \\
\text { vibrations were recorded using a six-channel Cityshark datalogger connected to one Lennartz LE-3D } \\
0.2 \mathrm{~Hz} \text { triaxial sensor. The H/V ratio was calculated using Geopsy software. }\end{array}$ \\
\hline
\end{tabular}

Then, all the available data and ArcMap software were used to develop a new map of soil predominant periods in Barcelona (see Fig. 3). The results show four clear soil zones for different ranges of periods. The first zone, in red, has the highest periods, and starts on the coastline. The last zone, in green, has the smallest periods and is in the highest zones of the city.

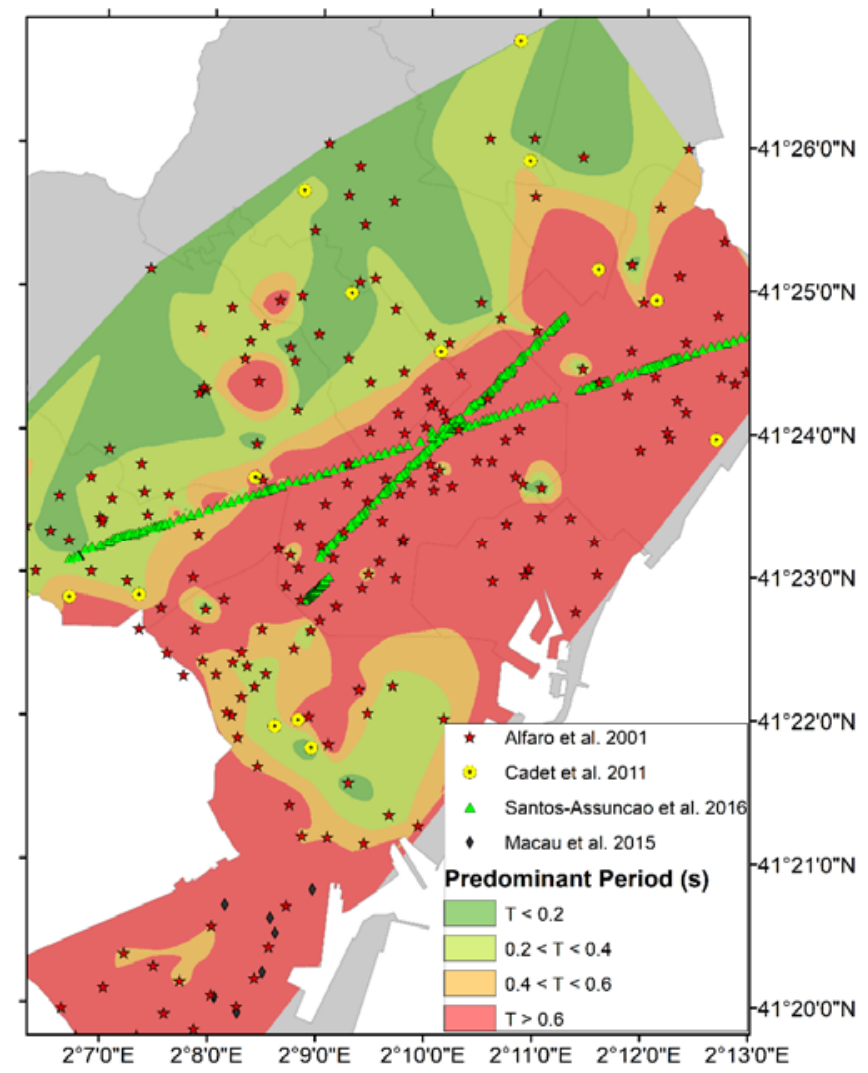

Fig. 3. Microzonation map of Barcelona based on soil periods. The points represent the available experimental data. 
A comparison between the resulting map and the topography and microzonation map of Cid et al. [10] (see Fig.1) showed interesting results. A relationship was found between three parameters: soil period, soil type, and elevation. Rocky soils are present in the highest zones with the smallest periods (near zero), corresponding to Cid's zones III and IV; and soft soils are in areas near the coast with the highest periods, corresponding to Cid's zones I and II. With these results, a different range of periods could be assigned to each zone: Zone IV $-\mathrm{T}<0.2 \mathrm{~s}$, Zone III $-0.2 \mathrm{~s} \leq \mathrm{T} \leq 0.4 \mathrm{~s}$, and Zones I and II $-\mathrm{T}>0.4 \mathrm{~s}$.

The ranges of predominant frequencies obtained by Cadet et al. [14] were similar to those obtained in this study. A summary of representative values of elevation, predominant period, predominant frequency [14], geomorphology [10], and shear-wave velocity $\left(\mathrm{Vs}_{30}\right)$ [14] for each zone is presented in Table 3.

Table 3. Summary of parameters of interest: microzonation zones, topography, geomorphology, $\mathrm{Vs}_{30}$, predominant frequency and fundamental period obtained in this study.

\begin{tabular}{|c|c|c|c|c|}
\hline Zones [10] & I & II & III & IV \\
\hline Elevation (m) & $0-15$ & $15-60$ & $60-125$ & $>125$ \\
\hline Predominant period, T (seg.) & $>0.40$ & $>0.40$ & $0.20-0.40$ & $<0.20$ \\
\hline $\begin{array}{c}\text { Predominant frequency (Hz) from } \\
\text { Cadet } \text { et al. [14] }\end{array}$ & $0.6-1.9$ & $0.8-2.1$ & $1.4-5.8$ & Unreliable \\
\hline Geomorphology [10] & $\begin{array}{c}\text { Recent } \\
\text { quaternary }\end{array}$ & $\begin{array}{c}\text { Ancient } \\
\text { quaternary }\end{array}$ & $\begin{array}{c}\text { Ancient quaternary } \\
\text { and rocky outcrop }\end{array}$ & $\begin{array}{c}\text { Rocky } \\
\text { outcrop }\end{array}$ \\
\hline $\mathrm{Vss}_{30}$ (m/s) from Cadet et al. [14] & 218 & 398 & 422 & 742 \\
\hline
\end{tabular}

\section{Crossing period maps}

The characteristics of the site affect the frequency and duration of ground motions. The site period (T) depends on the thickness of the layers $(H)$ and on the corresponding shear-wave velocities $(V s)$, according to the following approximate equation: $T=4 \cdot H / V S$. In most cases, structures built on rocky sites will be subjected to short-period excitations, while, under earthquake excitations, soft soils result in long-period motions. In addition, thin and soft soil layers over rigid bedrock may cause high-amplitude, short-period amplification. The ratio between the site period and the building period is important in estimating the resonance effects [21].

Areas of increased hazard caused by interaction and resonance effects between the soil response and the structural response can be detected by crossing the obtained building period map with the soil period map. Fig. 4 shows the results obtained by crossing both maps. Three zones were defined based on the similarity of the soil and building periods. Zones with increased probability of amplification due to a resonance effect are shown in red. These zones present differences in the range of $\pm 0.20 \mathrm{~s}$ between the building and soil fundamental periods. This difference corresponds to the standard error of Equation (1) [22]. In the case of moderate resonance zones (yellow), differences of between \pm 0.21 and $\pm 0.50 \mathrm{~s}$ were found. For the lower resonance zones (green), differences of $\pm 0.51 \mathrm{~s}$ or higher were defined. 
At first glance, the neighborhoods of Gràcia, Poble Sec, Sant Antoni, El Raval, and Sants are the most affected in the city center. These zones are correlated with the construction year and the structural typology. Most of the buildings were constructed in the $19^{\text {th }}$ century and the predominant typology is URM. URM is the most commonly used structural typology for buildings worldwide and the one that has caused the most damage and death, due to its high vulnerability to seismic events [23].
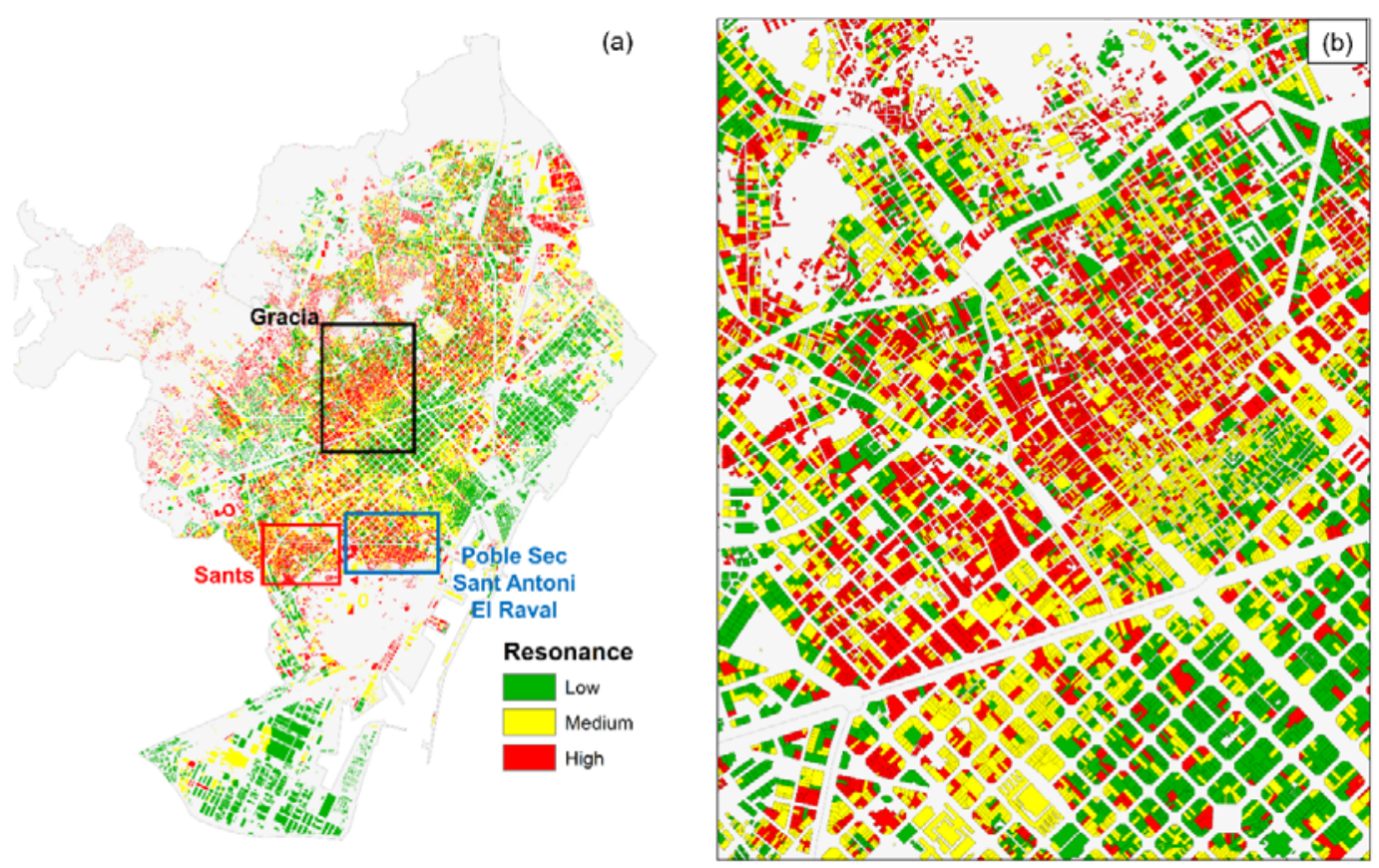

Fig. 4. (a) Resonance zones in Barcelona and (b) zoom-in of Gracia district.

\section{Discussion and Conclusions}

Although Barcelona is a city located in a low-to-moderate seismic hazard region, the exposed value and vulnerability are high, so the seismic risk is significant and mitigation studies are highly recommended. As the occurrence of an earthquake cannot be predicted, the only way to mitigate the effects generated by these events is to strongly influence prevention, in terms of structural safety in the design and seismic-resistant construction of buildings and infrastructures, and the planning and management of an emergency situation immediately after the occurrence of an earthquake.

In this study, soil and building period maps of Barcelona were generated. With the cross-correlation and analysis of both maps, a new map was developed highlighting the areas where soil-building resonance phenomena are expected. This study makes a significant contribution to awareness of the seismic risk in the city, when local effects are considered in regional and local seismic hazard studies. The maps developed herein can help to reduce the seismic risk, since special attention can be devoted to structures that are vulnerable to resonance effects. In addition, a microzonation map, based on the predominant soil periods, can be implemented in structural regulations to develop improved design spectra based on the site-specific period. 
As mentioned in the introduction, these studies complement soil-structure interaction (SSI) analyses [7-9]. SSI effects refer to modification of the building response due to the characteristics of the site. This effect is generally seen in buildings constructed on soft soils [24]. In addition, the SSI effect is defined as the process in which the soil's response modifies the response of the structure, and the structure influences the response of the soil [25].

Conventional structural codes do not consider SSI effects, since in most cases it is more conservative to use structural regulations. However, the effect of SSI is prominent when the structure and soil periods are similar. Bard et al. [26] demonstrated that the effects of the structure are greater when the soil-structure system period is close to the fundamental period of the ground. These effects should be considered, at least, with approaches such as that proposed in the National Institute of Standards and Technology (NIST) 12917-21 report [27]. Here, the structure-to-soil stiffness ratio, $r=h /\left(V_{S} \cdot T\right)$, is a recommended measure that indicates when SSI effects become relevant. The $h$ is the effective height to the center of mass for the first mode shape, $V s$ is the effective shear-wave velocity (e.g. the shear-wave velocity to a depth of 30 meters, $V S_{30}$ ), and $T$ is the fundamental period of vibration. Values of $r$ above 0.1 would indicate that SSI effects should be considered.

Another interesting aspect to consider in the evaluation of the seismic response of soils and structures is the presented by Macau et al. [20]. These authors show how H/V measures in shallow quaternary layers in the Llobregat Delta exhibit a second peak corresponding to another period of the soil. This peak could also be related to the building periods, so it would be interesting to take into account these values in future studies.

\section{Acknowledgments}

We thank Lucille Banham for her assistance in the preparation of the English manuscript. This research was partially funded by the Spanish Government's Ministry of Economy and Competitiveness (MINECO) and by the European Regional Development Fund (ERDF) of the European Union (EU) through the project referenced as CGL2015-65913-P (MINECO/ ERDF, EU). The first author is supported by a Ph.D. scholarship grant from the Government of Panama's Institute for the Training and Development of Human Resources (IFARHU) and the National Secretariat of Science, Technology, and Innovation (SENACYT).

\section{References}

[1] Franke KW, Ulmer KJ, Ekstrom LT, Meneses JF. Clarifying the differences between traditional liquefaction hazard maps and probabilistic liquefaction reference parameter maps. Soil Dyn Earthq Eng 2016;90:240-9. doi:10.1016/j.soildyn.2016.08.019.

[2] Fatahi B, Tabatabaiefar H, Samali B. Soil-structure interaction vs Site effect for seismic design of tall buildings on soft soil. Geomech Eng 2014;6:293-320.

[3] Goded T, Buforn E, Macau A. Site effects evaluation in Málaga city’s historical centre (Southern Spain). Bull Earthq Eng 2012;10:813-38. doi:10.1007/s10518-011-9337-4.

[4] Navarro M, García-Jerez A, Alcalá FJ, Vidal F, Enomoto T. Local site effect microzonation of Lorca town (SE Spain). Bull Earthq Eng 2014;12:1933-59. doi:10.1007/s10518-013-9491-y.

[5] Nakamura Y. A method for dynamic characteristics estimation of subsurface using microtremor on the ground surface. Q Rep Railw Tech Reasearch Inst 1989;30:25-33. 
[6] Dikmen SÜ, Tanırcan G. Site amplification and resonance frequency in the urban environment. Soil Dyn Earthq Eng 2018;105:160-70. doi:10.1016/j.soildyn.2017.12.010.

[7] Stanko D, Markušić S, Strelec S, Gazdek M. HVSR analysis of seismic site effects and soil-structure resonance in Varaždin city (North Croatia). Soil Dyn Earthq Eng 2017;92:666-77. doi:10.1016/j.soildyn.2016.10.022.

[8] Tabatabaiefar H, Fatahi B, Ghabraie K, Zhou W-H. Evaluation of numerical procedures to determine seismic response of structures under influence of soil-structure interaction. Struct Eng Mech 2015;56:27-47.

[9] Fatahi B, Tabatabaiefar H, Samali B. Performance Based Assessment of Dynamic Soil-Structure Interaction Effects on Seismic Response of Building Frames. Georisk 2011 Geotech. Risk Assess. Manag., Atlanta, Georgia: American Society of Civil Engineers; 2011, p. 344-51.

[10] Cid J, Susagna T, Goula X, Chavarria L, Figueras S, Fleta J, et al. Seismic zonation of Barcelona based on numerical simulation of site effects. Pure Appl Geophys 2001;158:2559-77. doi:10.1007/PL00001186.

[11] Jiménez MJ, García-Fernández M, Zonno G, Cella F. Mapping soil effects in Barcelona, Spain, through an integrated GIS environment. Soil Dyn Earthq Eng 2000;19:289-301. doi:10.1016/S0267-7261(00)00007-5.

[12] Figueras S, Schmidt-Díaz V, Susagna T, Fleta J, Goula X, Roca A. Preliminary study of microzonation of Barcelona (Spain). Fifth Int. Conf. Seism. Zo., Nice, France: 1995, p. 731-738.

[13] Alfaro A, Pujades LG, Goula X, Susagna T, Navarro M, Sanchez J, et al. Preliminary map of soil's predominant periods in Barcelona using microtremors. Pure Appl Geophys 2001;158:2499-511. doi:10.1007/PL00001182.

[14] Cadet H, Macau A, Benjumea B, Bellmunt F, Figueras S. From ambient noise recordings to site effect assessment: The case study of Barcelona microzonation. Soil Dyn Earthq Eng 2011;31:271-81. doi:10.1016/j.soildyn.2010.07.005.

[15] Lantada N, Irizarry J, Barbat AH, Goula X, Roca A, Susagna T, et al. Seismic hazard and risk scenarios for Barcelona, Spain, using the Risk-UE vulnerability index method. Bull Earthq Eng 2010;8:201-29. doi:10.1007/s10518-009-9148-Z.

[16] Milutinovic Z, Trendafiloski G. RISK-UE: an advanced approach to earthquake risk scenarios with applications to different European towns. WP04 Vulnerability of current buildings. 2003.

[17] CEN. European Standard EN 1998-1:2005 Eurocode 8: Design of structures for earthquake resistance. Part 1: General rules, seismic actions and rules for buildings English version. Brussels, Belgium: 2004.

[18] Kwon OS, Kim ES. Evaluation of building period formulas for seismic design. Earthq Eng Struct Dyn 2010;39:1569-83. doi:10.1002/eqe.998.

[19] Santos-Assuncao S, Perez-Gracia V, Salinas V, Caselles O, Gonzalez-Drigo JR, Pujades LG, et al. GPR Backscattering Intensity Analysis Applied to Detect Paleochannels and Infilled Streams for Seismic Nanozonation in Urban Environments. IEEE J Sel Top Appl Earth Obs Remote Sens 2016;9:167-77. doi:10.1109/JSTARS.2015.2466235.

[20] Macau A, Benjumea B, Gabàs A, Figueras S, Vilà M. The Effect of Shallow Quaternary Deposits on the Shape of the H/V Spectral Ratio. Surv Geophys 2015;36:185-208. doi:10.1007/s10712-014-9305-z.

[21] Elnashai A-S, Sarno L. Fundamentals of earthquake engineering. vol. 43. John Wiley. 2008.

[22] Goel RK, Chopra AK. Period Formulas for Moment-Resisting Frame Buildings. J Struct Eng 1997;123:1454-61. doi:10.1061/(ASCE)0733-9445(1997)123:11(1454).

[23] Pinzón LA, Pujades LG, Diaz SA, Alva RE. Do Directionality Effects Influence Expected Damage? A Case Study of the 2017 Central Mexico Earthquake. Bull Seismol Soc Am 2018;108:2543-55. doi:10.1785/0120180049.

[24] Bard PY, Gueguen P, Kham M, Semblat JF. Site-city interaction. In: Oliveira CS, Roca A, Goula X, editors. Assess. Manag. Earthq. Risk, New York: Springer; 2005, p. 530.

[25] Tuladhar R, Maki T, Mutsuyoshi H. Cyclic behavior of laterally loaded concrete piles embedded into cohesive soil. Earthq Eng Struct Dyn 2008;37:43-59. doi:10.1002/eqe.

[26] Bard P-Y, Gueguen P, Wirgin A. A note on the seismic wavefield radiated from large building structures into soft soils. 11th World Conf Earthq Eng 1996.

[27] National Institute of Standards and Technology Grant Contract Report (NIST GCR) 12-917-21. Soilstructure interaction for building structures. NEHRP consultants Joint Venture and National Institute of Standards and Technology, U.S. Department of Commerce, 2012. 